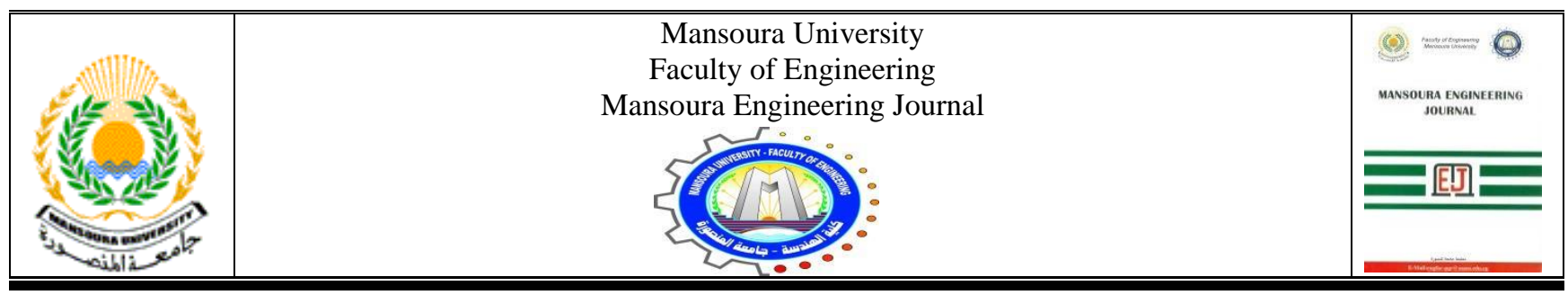

\title{
A Preliminary Reduced Three Dimensional Model of Regular Diagrid Tall Buildings for Fast Seismic Analysis
}

\author{
M. Naguib, Ahmed A.Ghaleb, S. Lotfy and Ahmed M. Yousef
}

\author{
KEYWORDS: \\ Diagrid system; \\ Reduced model; \\ Equivalent lateral \\ force; Dynamic \\ response spectrum; \\ Linear time history.
}

\begin{abstract}
This paper introduces a reduced 3D diagrid model to save both time and computer memory for modeling and seismic analysis. The analysis of different models of steel diagrid tall buildings with variable heights and inclinations of diagrid is performed applying a finite element program SAP2000. Three clusters of diagrid buildings with different aspect ratios (height-to-width) and reliable optimum inclination angles are examined. The cross sections for diagrid elements are designed using stiffness -based design method which is more reliable for diagrid buildings. The 3D finite element model as a real structure and the proposed reduced seismic model that reducing finite element model up to twenty percent by canceling a specified number of floors with restrictions in modeling are employed. Equivalent lateral Force, dynamic response spectrum, and linear time history analyses are considered. A comparison of obtained results in terms of lateral displacement at top of the building, first mode period of vibration and base shear are presented. The conclusions reveal that the proposed reduced 3D model is convince for preliminary modeling and analysis of regular diagrid buildings in existence of seismic loads.
\end{abstract}

\section{INTRODUCTION}

$\mathrm{T}$ HE development of structural engineering has become more effective in the present decade. The fast development of tall buildings and software to analyze

Received: (25 August, 2020) - Revised: (10 January, 2021) - Accepted: (6 Feburary, 2021)

Corresponding author: M. Naguib, Emeritus professor in Department of Structural Engineering, Faculty of Engineering, Mansoura University, Mansoura, Egypt.(e-mail: Naguib_2017@mans.edu.eg)

Ahmed A. Ghaleb, Emeritus Associate professor in Department of Structural Engineering, Faculty of Engineering, Mansoura University, Mansoura, Egypt.

S. Lotfy, Assistant lecturer in Civil Engineering Department, Misr Higher Institute for Engineering and Technology, Mansoura, Egypt.

Ahmed M. Yousef, rofessor in Department of Structural Engineering, Faculty of Engineering, Mansoura University, Mansoura, Egypt. these buildings invent new systems for lateral load resistance. One of the innovations complex systems is the diagrid system which gets the concerns of architectures and civil engineers. The main issue for the system is how to handle the complicated steel diagrid structures which have free-form in shape. The system operates as an integrated single unit. Diagrids are a design strategy that can resist gravity and, lateral loads through the triangulated framework shape members which eliminate vertical columns requirements. The main idea of the diagrid is the possible saving due to the removal of vertical columns. This system gives a large open area, and charming exposure. Diagrid structure is modeled as a vertical cantilever and subdivided longitudinally into a triangular diagrid module according to the repetitive diagonal 
pattern. Each diagrid module is a single level of diagonals that elongate to a number of stories as shown in Fig. 1.

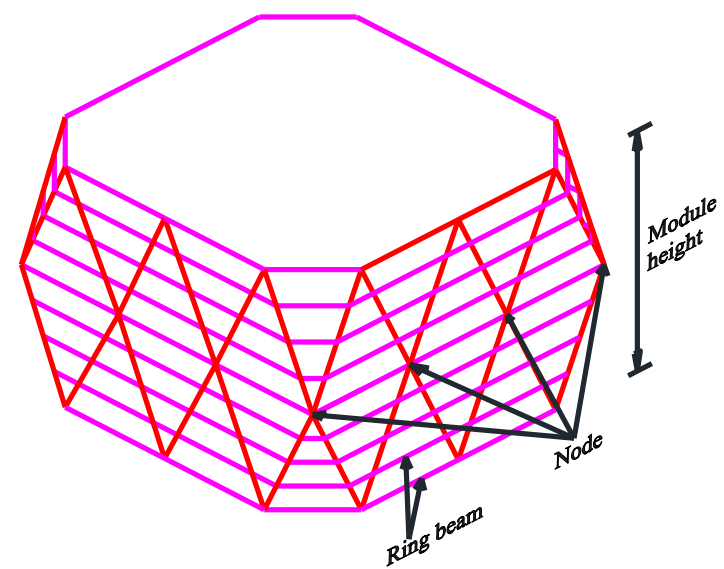

(a) $3 \mathrm{D}$ view

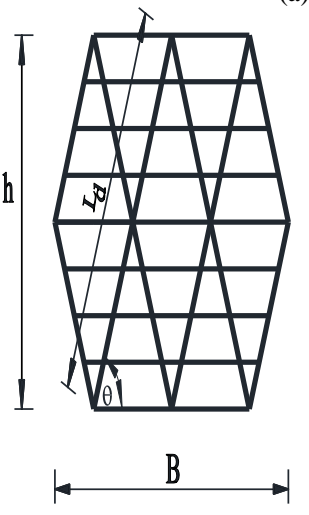

(b) $\mathrm{x}-\mathrm{z}$ view

Fig. 1. Typical module of eight floors.

Some studies on the diagrid buildings including the diagrid inclination angle, the node connections, and seismic performance factors are indicated. The optimal angle of diagrid elements was studied by [1]-[5]. The results showed that the optimal angle of high-rise diagrid buildings falls within $55^{\circ}$ to $75^{\circ}$. A coupling of optimization and robustness methods for the preliminary design of steel diagrid tall buildings using the principle of virtual work were proposed by [6]. A lot of researchers examined the creation and development of the node connections in diagrid structures [7][10]. Some studies on the seismic performance factors for diagrid buildings were conducted by [11]-[14]. A new method for determining seismic performance factors of steel diagrid framed systems for a number of archetypes with different parameters are examined by [11]. The proposed method reduced the efforts to compute the response modification factor based on nonlinear static analysis rather than the iterative nonlinear dynamic time history analysis. The interior core is not required to resist lateral load in the diagrid system [3]. Building height is an effective parameter on the optimum angle of diagonals [15]. As the lever arm of peripheral diagonal columns, the diagrid structural system is more effective in lateral load resistance [16]. Diagrid systems can improve the performance against seismic loads based on ductility, strength and stiffness [17].
The main objective of this paper is to propose a reduced 3D model of regular diagrid tall buildings for quick seismic analysis. Three clusters of diagrid buildings with various aspect ratios and different diagrid inclination angle $60.94^{\circ}$, $67.38^{\circ}, 71.56^{\circ}$ measured from the horizontal are considered for the analysis. All selected clusters were introduced by [5]. Equivalent lateral force, dynamic response spectrum, and linear time history analyses have been performed to evaluate the applicability to use the reduced seismic model in the preliminary analysis.

\section{VERIFICATION MODEL}

In order to verify the suggested mathematical model, a thirty six story steel diagrid building by [16] is simulated using SAP2000. The model is shown in Fig. 2. The cross sections per IS:800-2007 [18] are shown in Table 1. The lateral seismic load and the lateral displacement along the height of the building are shown in Figs. 3, and 4. It can be seen that, good agreement is achieved, so this model is accurate enough to conduct the seismic analysis.

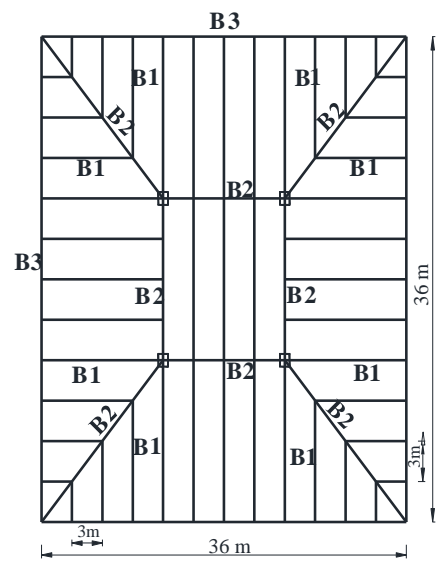

(a) Plan

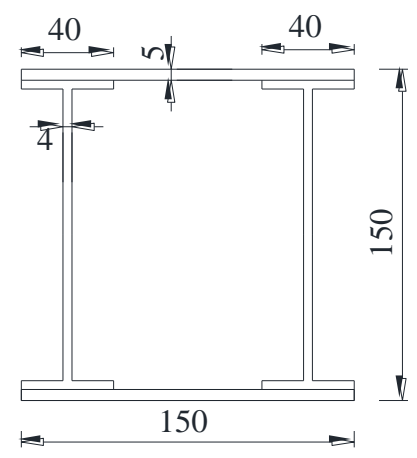

(b) Columns cross sections (dimensions in $\mathrm{cm}$ )

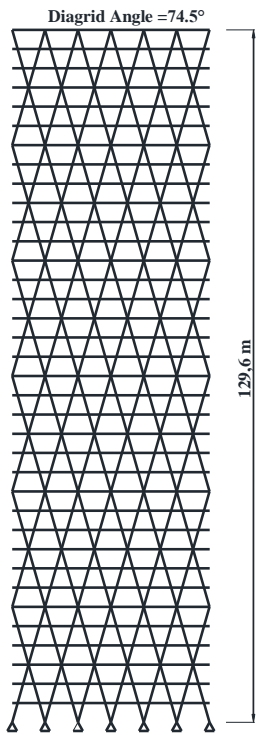

(c) Elevation

Fig. 2. Configuration for 36- story diagrid building

Table 1

Various cross sections for thirty-six story diagrid building

\begin{tabular}{|c|c|c|c|}
\hline Stories & Diagrid $(d \times t)$ & Columns & \multirow{3}{*}{$\begin{array}{c}\text { Beams } \\
\text { B1 = B3 =ISMB 550 } \\
\text { B2= ISWB } 600 \text { with top } \\
\text { and bottom Cover plate of } \\
22 \mathrm{~cm} \times 5 \mathrm{~cm}\end{array}$} \\
\hline $1-18$ & $45 \mathrm{~cm} \times 2.5 \mathrm{~cm}$ & \multirow{2}{*}{$\begin{array}{c}150 \mathrm{~cm} \times 150 \mathrm{~cm} \\
\text { Built up } \\
\text { columns }\end{array}$} & \\
\hline $19-36$ & $37.5 \mathrm{~cm} \times 1$. & & \\
\hline
\end{tabular}




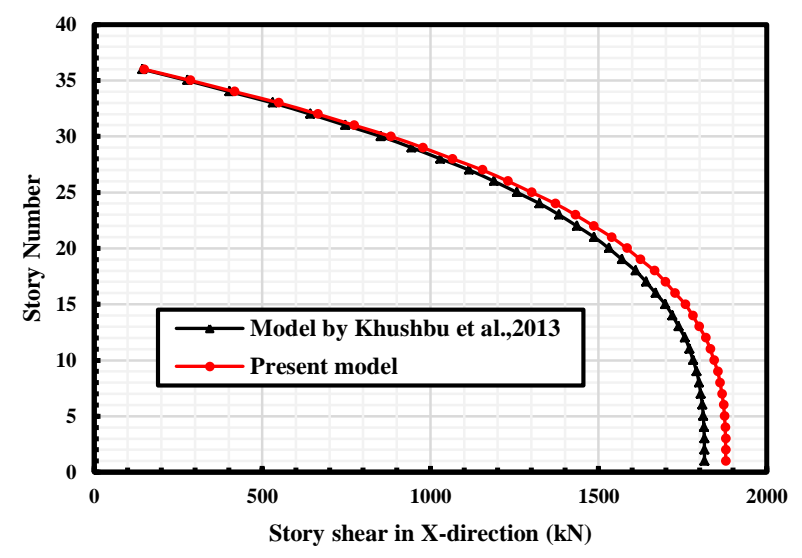

Fig. 3. Story shear along height of 36- story diagrid building.

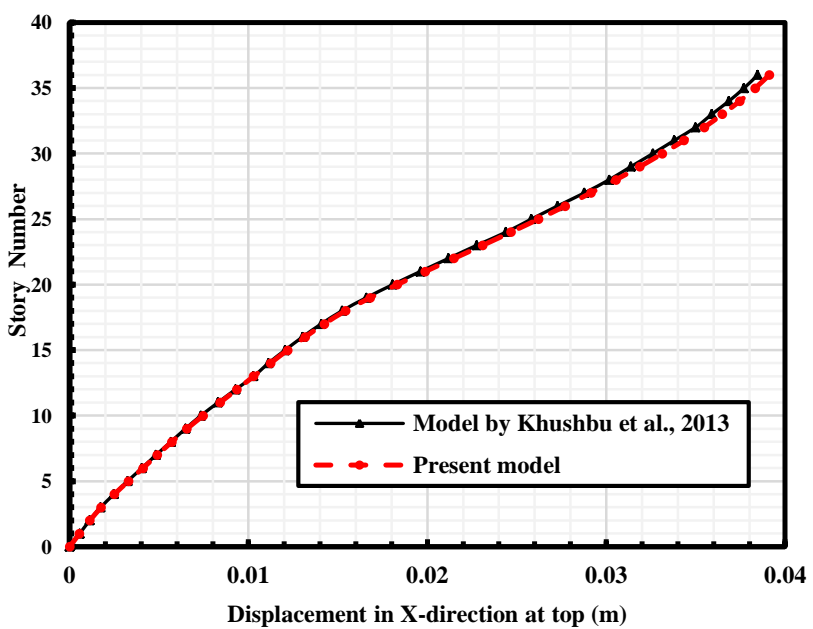

Fig. 4. Lateral displacement a long height of 36- story diagrid building

\section{Methodologies}

\section{A. Three-dimension Model}

Three-dimensional modeling of diagrid buildings is essential because of the global behavior which cannot be simplified. It presents a more acceptable behavior to the real structure but, it needs more time for modeling and analysis with enlargement in internal memory of computers. In threedimension modeling, the beams, columns and diagonals are treated as line elements and the slabs as shell elements. The structure is exposed to complete seismic load and resist the load by the gross stiffness and mass.

\section{B. Reduced Diagrid Model}

In this paper, the simplified shear beam model that introduced by [19] was followed and a simplified diagrid model is proposed by defining an equivalent stiffness and mass for diagrid elements, as shown in Fig. 5. This approach reduces the modeling time and calculations steps. The equivalent stiffness is computed herein based on the formula of springs in series as follows

$$
\frac{1}{\mathrm{k}_{\mathrm{eq}}}=\frac{1}{\mathrm{k}_{1}}+\frac{1}{\mathrm{k}_{2}}+\frac{1}{\mathrm{k}_{3}}
$$

The mass is automatically modified for the slabs and beams based on the cancelled floors. Since, the mass for columns and diagrids are modified based on the following equation

$$
\frac{1}{\mathrm{~m}_{\mathrm{eq}}}=\frac{1}{\mathrm{~m}_{1}}+\frac{1}{\mathrm{~m}_{2}}+\frac{1}{\mathrm{~m}_{3}}
$$

Since, the seismic load depends on the mass; the reduced load is automatically modified with the reduction of the mass.
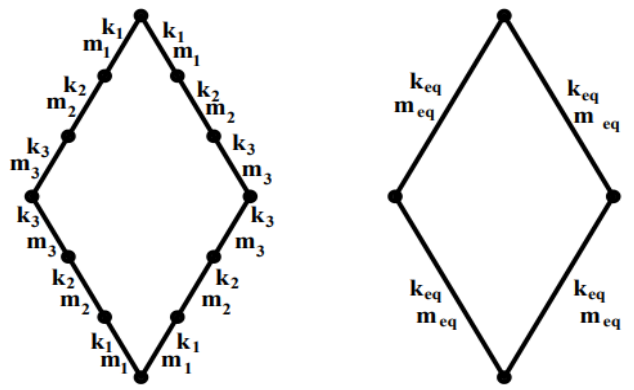

Fig.5. Equivalent Stiffness and mass for diagrid element

In order to simplify the model, the procedures are as follows; numbers of floors are reduced to be a half, third, quarter, or fifth of the total numbers. The condition for different reduced floors is shown in Table 2. The stiff solution of slabs is modeled by constrained the slab as rigid diaphragm. The equivalent stiffness and mass for various elements is defined by factoring the stiffness and the mass modifier in finite element modeling (based on property/stiffness modifiers [20]). The length of vertical columns and diagonal columns are varying increased from two to five times of the original element according to the cancelled number of floors. The seismic load is automatically modified according to the reduction of the introduced equivalent mass. The results of base shear and internal forces are magnified to more equalize the original model by a factor equal to (no of cancelled floors +1 ). Figures 6 to 8 show samples of the reduced modules for diagrid.

TABLE 2

Condition for different reduced models

\begin{tabular}{c||c||c||c||c}
\multicolumn{1}{c||}{$\begin{array}{c}\text { No of floors in half } \\
\text { module }\end{array}$} & \multicolumn{4}{c|}{ No of cancelled floors } \\
\cline { 2 - 4 } & $\mathbf{1}$ & $\mathbf{2}$ & $\mathbf{3}$ & $\mathbf{4}$ \\
\hline Two & $\sqrt{ }$ & $\times$ & $\times$ & $\times$ \\
\hline Three & $\times$ & $\sqrt{ }$ & $\times$ & $\times$ \\
\hline Four & $\times$ & $\sqrt{ }$ & $\sqrt{ }$ & $\times$ \\
\hline Five & $\times$ & $\times$ & $\times$ & $\sqrt{ }$
\end{tabular}

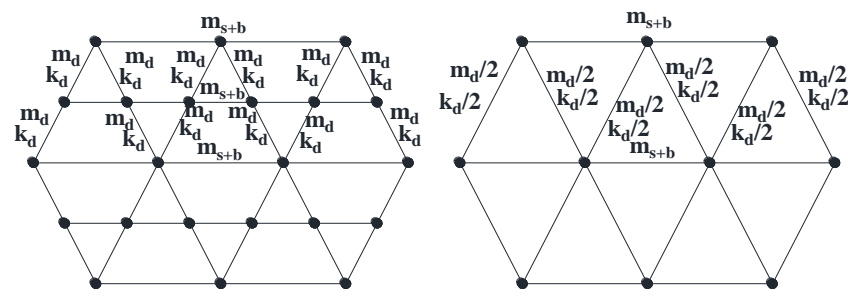

(a) Original

(b) Reduced to half

Fig. 6. Typical module of four floors 


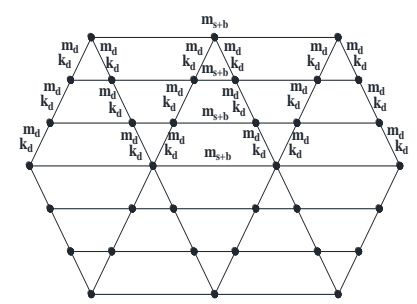

(a) Original

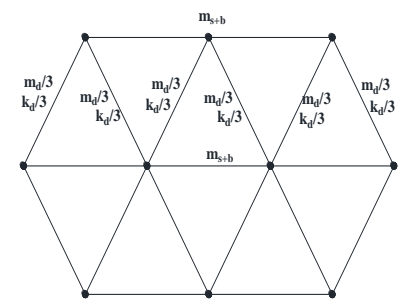

(b) Reduced to third

Fig. 7. Typical module of six floors

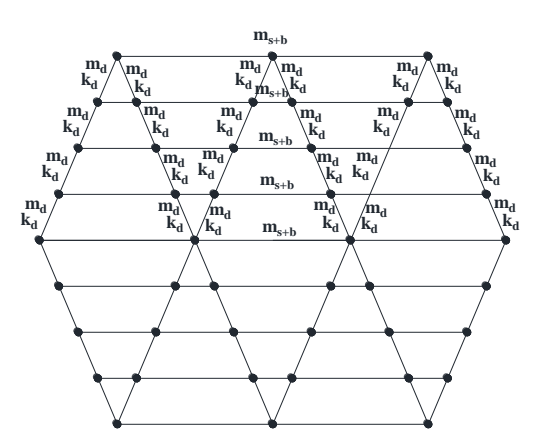

(a) Original model

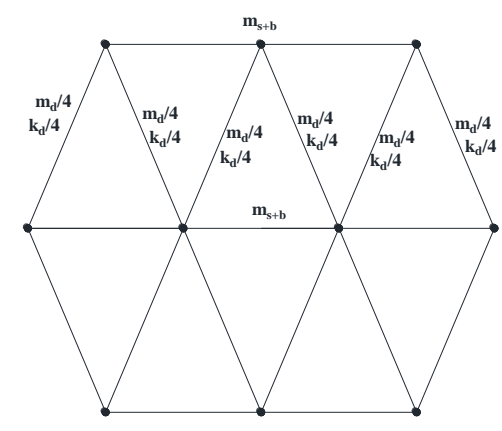

(b) Reduced to quarter Fig. 8. Typical module of eight floors

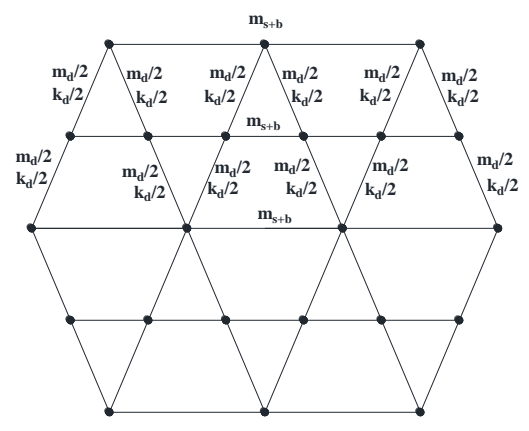

(c) Reduced to half

\section{Finite Element MOdeL}

Finite element models are considered using SAP2000. Two types of elements are used to simulate beams, diagonals, columns, and slabs. The simulation of beams, columns, and diagonals is done by using frame element (line element). The frame element has six degrees of freedom which is branched to three translations and three rotations. The simulation of slabs is done by using shell element (plane element). The shell element has six degrees of freedom which is branched to three translations and three rotations. All base joints are restrained as fixed in all directions. The methods for modeling are: three dimensional modeling which is referenced as original model and reduced 3D model which is referenced as reduced model. The original and the reduced three-dimension module of eight floors are shown in Fig. 9. The analysis is done using a work station PC with processor (Intel (R) Xeon (R) CPU E5620 @ $2.40 \mathrm{GHz} 2.40 \mathrm{GHZ}$ (2 processors)) and installed memory (RAM) 24.0 GB.

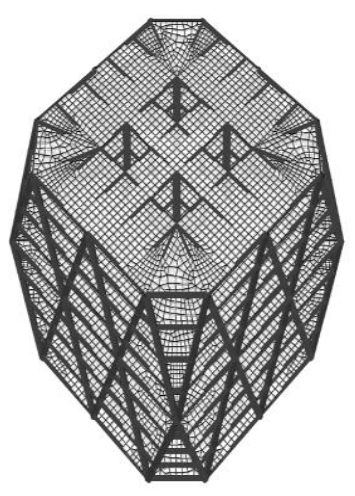

(a) Original

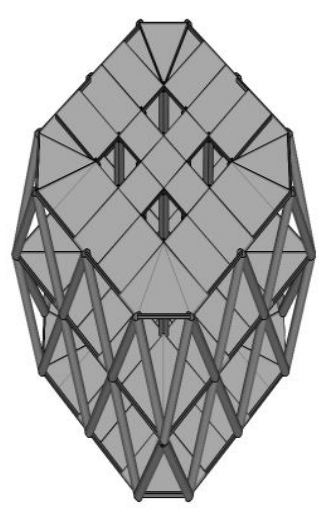

(b) Reduced to quarter
Fig. 9. Typical 3D module of eight floors

\section{Analysis Model Structures}

Three clusters are selected to cover the optimum range of diagrid inclination angles based on the state of art for diagrid buildings. The variations in the aspect ratio and the number of floors in typical module are suggested to check the reduced model results for various configurations. All clusters have a square plan dimension of $40.0 \mathrm{~m}$. Each cluster consists of six models with various aspect ratios. The first cluster has aspect ratio ranging from 6 to 3 , and its typical story height is $3.0 \mathrm{~m}$. The diagrid elements are connected to every 8 stories and make an inclination angle of $60.94^{\circ}$ measured from the horizontal. The second cluster has aspect ratio ranging from 8 to 4 , and its typical story height is $4.0 \mathrm{~m}$. The diagrid elements are connected to every 8 stories and make an inclination angle of $67.38^{\circ}$ measured from the horizontal. The third cluster has aspect ratio ranging from 8 to 3 and its typical story height is $4.0 \mathrm{~m}$. The diagrid elements are connected to every 10 stories and make an inclination angle of $71.56^{\circ}$ measured from the horizontal. The deformations have been controlled for buildings to behave linearly and elastically due to equivalent lateral seismic force mentioned in section VI. The cross sections for diagrid elements are empirically suggested using stiffness-based design according to the following formulas [1]:

$$
\begin{aligned}
A_{d f} & =\frac{\mathrm{M} \mathrm{L}_{\mathrm{d}}(1+\mathrm{S}) \alpha_{h} \mathrm{H}}{\left(\mathrm{N}_{\mathrm{F}}+\delta\right) E \mathrm{~B}^{2} \mathrm{hS} \sin \theta^{2}} \\
\mathrm{~A}_{\mathrm{dw}} & =\frac{\mathrm{V} \mathrm{L} \mathrm{L}_{\mathrm{d}}(1+\mathrm{S}) \alpha_{h}}{2 \mathrm{~N}_{\mathrm{w}} \mathrm{E} h \cos \theta^{2}}
\end{aligned}
$$

The three clusters are shown in Fig. 10. A standard steel ASTM A500 [21]: grade B is used. The 16 inner vertical columns are square steel tubes with $F_{y}=31.72 \mathrm{kN} / \mathrm{cm}^{2}$. They have outer dimensions varying between $135 \mathrm{~cm} \times 135 \mathrm{~cm}$ and $50 \mathrm{~cm} \times 50 \mathrm{~cm}$ and wall thicknesses range between $4.6 \mathrm{~cm}$, 
and $2.0 \mathrm{~cm}$. The diagrid elements are circular steel sections with $\mathrm{F}_{\mathrm{y}}=28.96 \mathrm{kN} / \mathrm{cm}^{2}$. They have an outer-diameter varying between $179.0 \mathrm{~cm}$ and $40.0 \mathrm{~cm}$ with wall thicknesses range between $6.0 \mathrm{~cm}$, and $1.3 \mathrm{~cm}$. Distribution of each diagrid element cross-section along height for the three clusters is shown in Fig. 11. Building models are generated using a FORTRAN program which is constructed by [5] for importing $\$ 2 \mathrm{~K}$ file to SAP2000 [7]. All masses are modeled as lumped translational masses in global axes at all joints of the model. The mass is sourced from dead load plus $25 \%$ of live load. The floor slabs are defined as concrete sections with compressive strength of $2.76 \mathrm{kN} / \mathrm{cm}^{2}$ and thickness of 20.0 $\mathrm{cm}$. All slabs (shell elements) are meshed with maximum size of $1.0 \mathrm{~m}$. The used outer beams outer rectangular tube $(30 \times$ $60 \mathrm{~cm})$ with wall thicknesses $(0.8 \times 1.3 \mathrm{~cm})$ and the used inner beams are rectangular tube $(20 \times 45 \mathrm{~cm})$ with wall thicknesses $(0.9 \times 1.4 \mathrm{~cm})$.

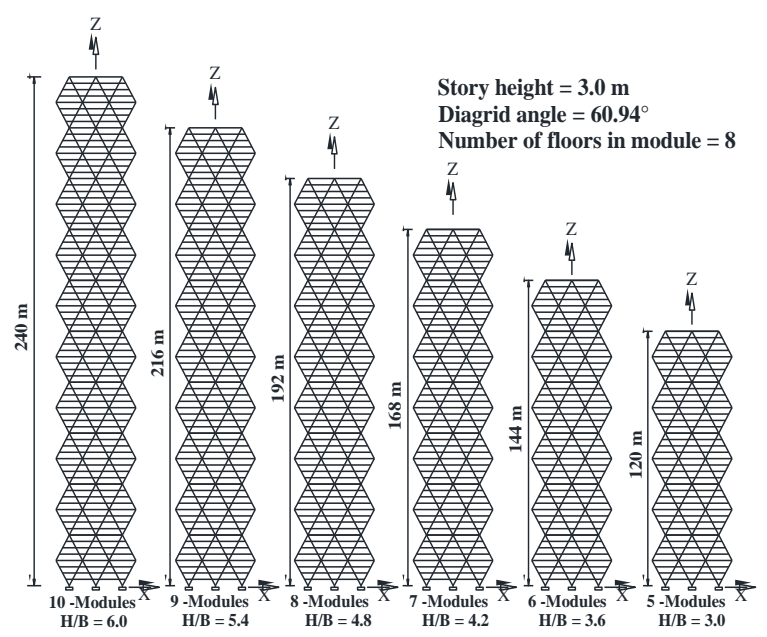

(a) X-Z view of cluster 1.

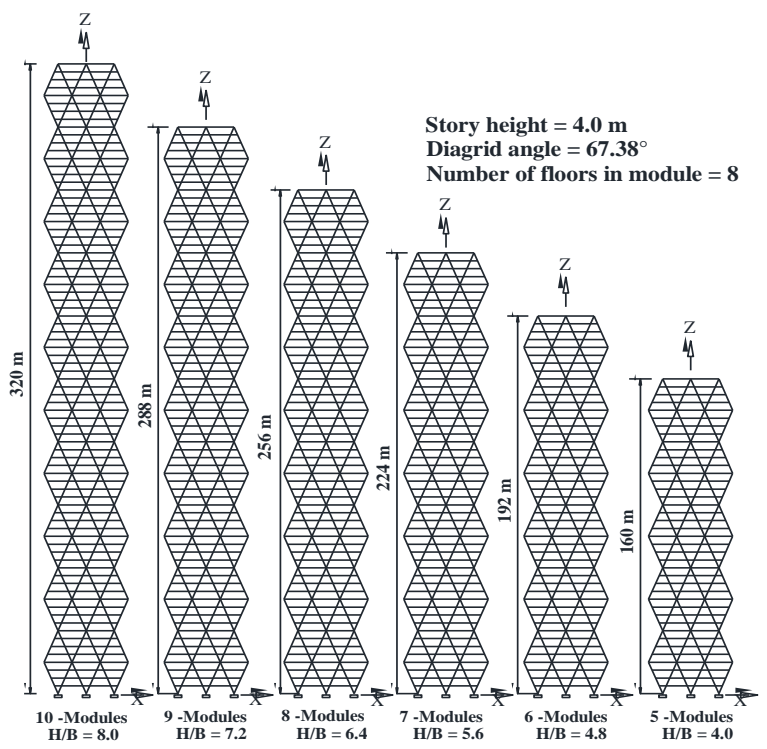

(b) X-Z view of cluster 2 .

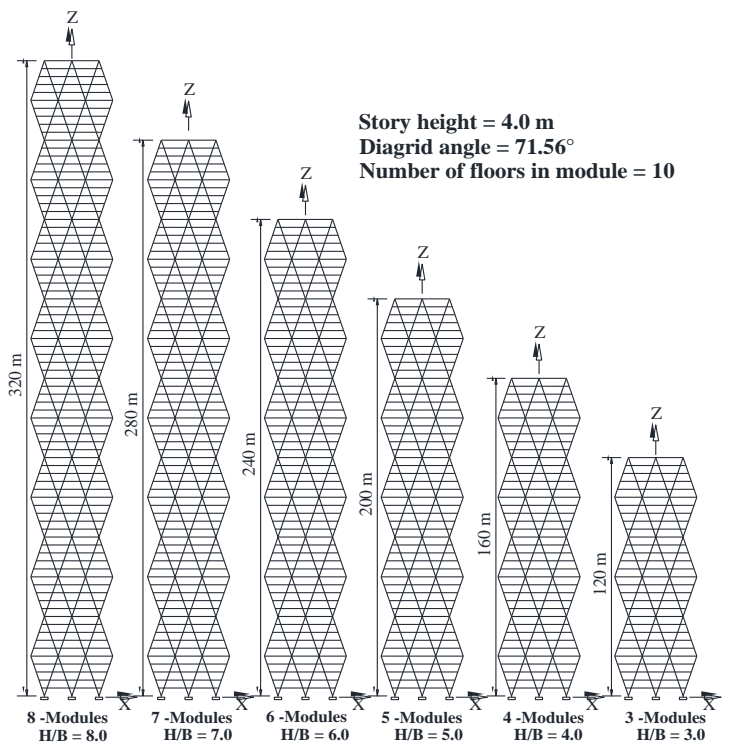

(c) $\mathrm{X}-\mathrm{Z}$ view of cluster 3 .

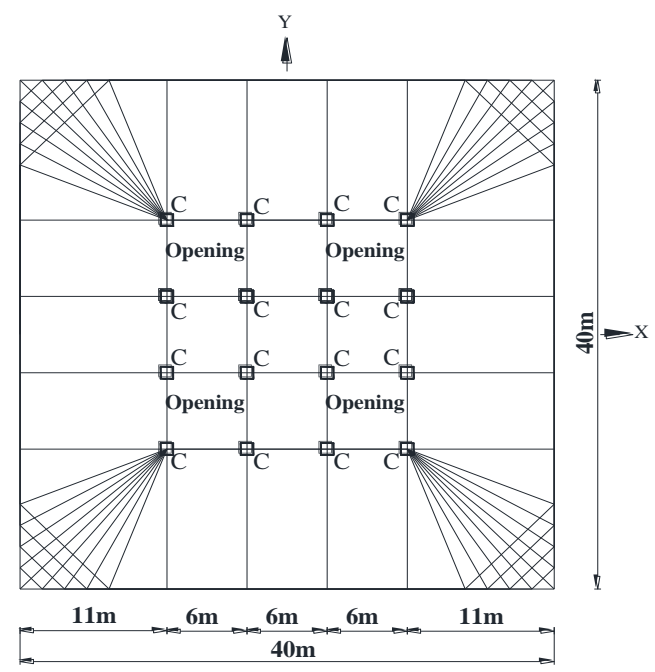

(d) Cumulative plan view of clusters 1 and 2

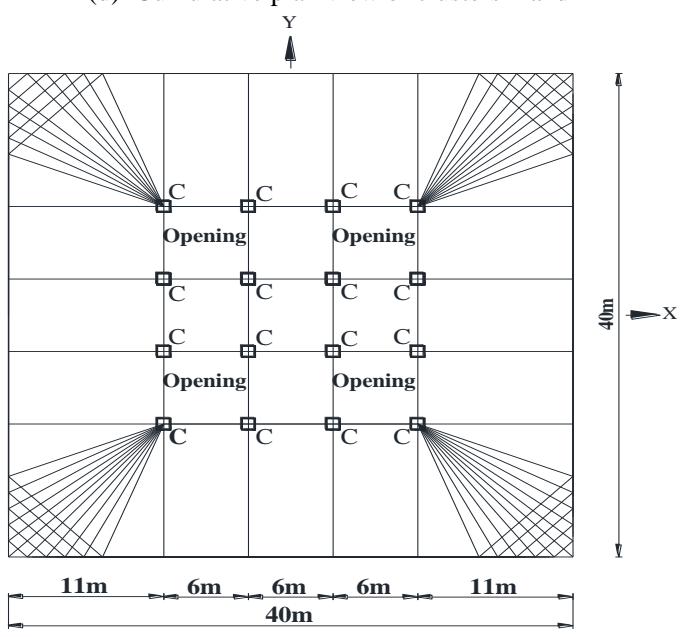

Note: $\mathbf{C}$ is vertical column

(e) Cumulative plan view of cluster 3 .

Fig. 10 Views for the three clusters 


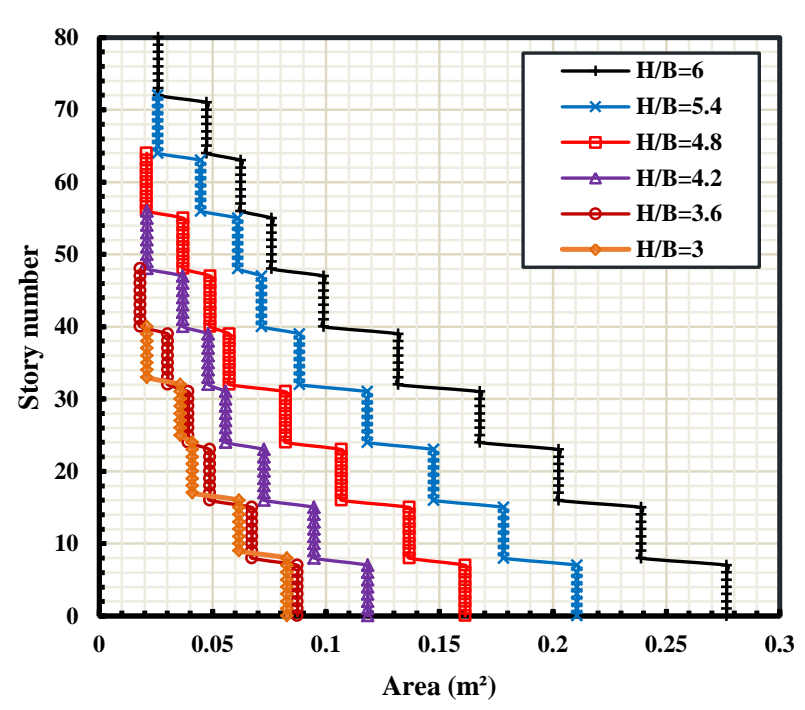

(a) Cluster 1

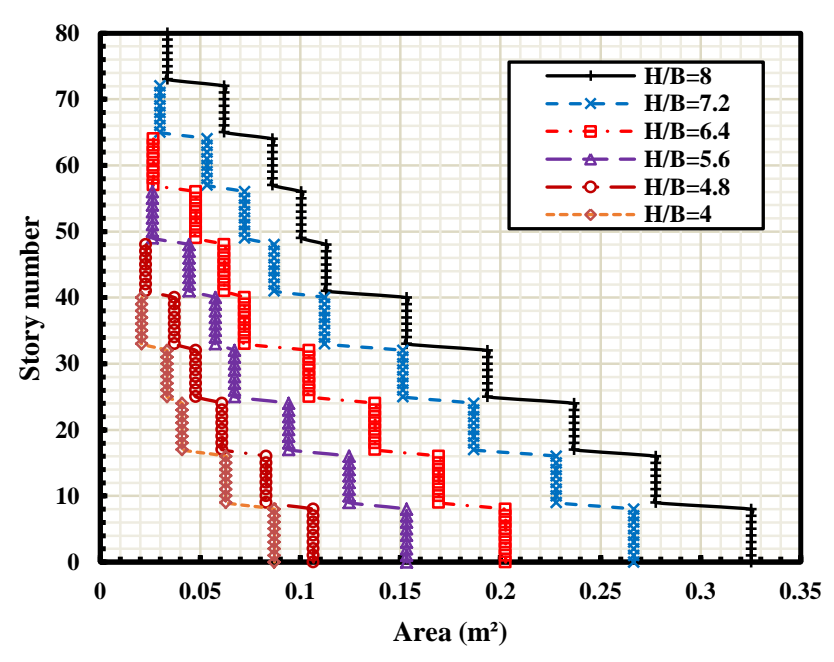

(b) Cluster 2

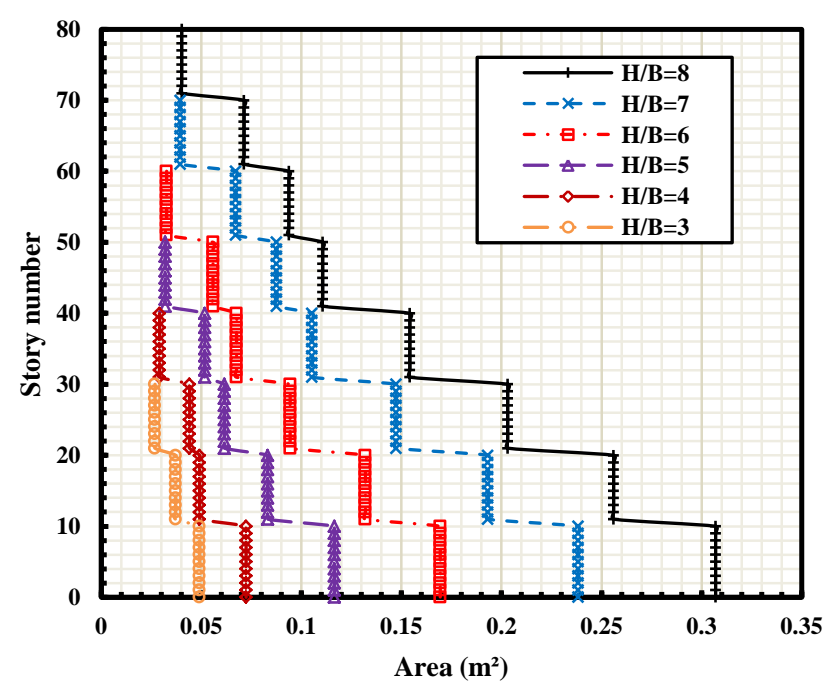

(c) Cluster 3

Fig. 11. Area of diagrid element for each floor

\section{LOADING ASSUMPTIONS}

All clusters are analyzed based on different methods of seismic analysis according to ASCE7-10 [22]. The methods are equivalent lateral force, dynamic response spectrum and time history analyses. Before seismic analysis, modal analyses are carried out for the elastic behavior with a number of modes achieving greater than or equal to $90 \%$ of mass participating ratio. All seismic loads are applied in X-direction. For the equivalent lateral force and dynamic response spectrum, the design seismic parameters are selected to match a moderate zone of earthquakes and to confirm the linear behavior as following [22]: $S_{D S}=0.2242 \mathrm{~g}, S_{D 1}=0.0816 \mathrm{~g}, C_{t}=0.02, x=0.75$, $R=1.0$, site class is $C, I_{e}=1.0$, and $T_{L}=6 \mathrm{~s}$. For the dynamic response spectrum, the response spectrum curve is generated as shown in Fig. 12. Incorporation of the member end forces is done using the complete quadratic combination (CQC) technique.

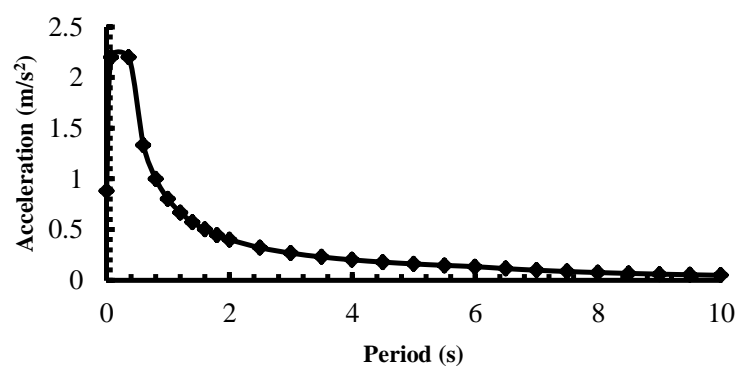

Fig. 12. Response spectrum curve

For the linear dynamic time history (Modal superposition), a Scaled El Centro acceleration record is used. El Centro earthquake record is extracted from Strong Motion Center [23] then, the baseline is corrected using SeismoSignal software [24] then, the record is scaled in the time domain to simulate the previous selected seismic parameters. ETABS [25] is used to extract the scaled El Centro record to match the same frequency content of El Centro record . Various spectrums and histories for the matching process are shown in Figs. 13 and 14. The analysis is done for $55 \mathrm{~s}$ with a time step of $0.02 \mathrm{~s}$.

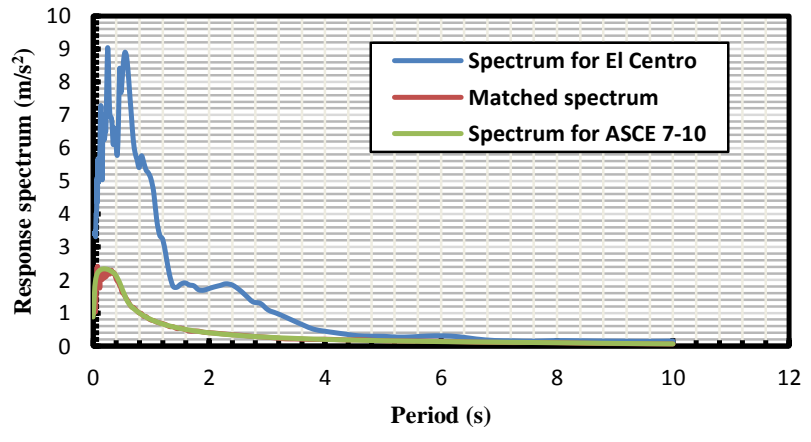

Fig. 13. Spectrum for the original and matched record 


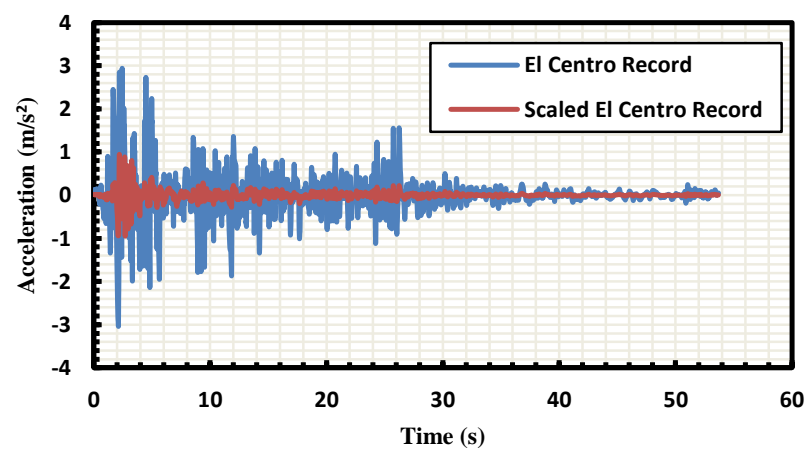

Fig. 14. Acceleration history for the original and matched record

The damping matrix is treated for dynamic response spectrum and time history analyses using Rayleigh damping equation [26] which in the form:

$$
[\mathrm{C}]=\alpha_{\mathrm{m}}[\mathrm{M}]+\beta_{\mathrm{k}}[\mathrm{K}]
$$

Where $\alpha_{\mathrm{m}}$ and $\beta_{\mathrm{k}}$ are two constants can be computed from the following equations:

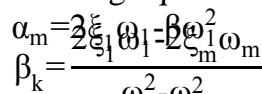

The firs $\varphi^{2}=\omega^{2}{ }^{2}$ de damping ratio is proposed by [27] for steel buildings as following:

$$
\xi_{1}=1.2+4.26 \mathrm{e}^{-0.013 \mathrm{H}}
$$

The higher modes damping ratios are obtained by [28] using the following equation:

$$
\xi(f)=\xi_{1}\left[1+\gamma_{m}\left(\frac{f_{n}}{f_{1}}-1\right)\right]
$$

Where; $\gamma_{\mathrm{m}}=0.13$ for steel braced frame buildings which can be used for diagrid structures.

The Rayleigh damping needs two significant modes of vibrations. The first $13^{\text {th }}$ modes of vibration satisfy the significant mass participation factor of almost $90 \%$ as shown in Table 3 for lateral translations. So, the first mode and the $13^{\text {th }}$ mode are satisfactory for the computations of Rayleigh

\begin{tabular}{|c|c|c|c|}
\hline \multirow[t]{2}{*}{ Cluster } & \multirow[t]{2}{*}{ H/B } & $\begin{array}{r}\text { IIRTEEN MODE } \\
\text { The cumulati } \\
\text { participating f } \\
\text { translat }\end{array}$ & $\begin{array}{l}\text { gnificant mass } \\
r \text { for the lateral } \\
X \text { and } Y\end{array}$ \\
\hline & & $X$-direction (\%) & Y-direction (\%) \\
\hline \multirow{6}{*}{1} & 6 & 89.7338 & 89.7338 \\
\hline & 5.4 & 90.2329 & 90.2329 \\
\hline & 4 & 90.4109 & 90.4109 \\
\hline & 4.2 & 90.986 & 90.986 \\
\hline & 3.6 & 91.2411 & 91.2411 \\
\hline & 3 & 91.3072 & 91.3072 \\
\hline \multirow{6}{*}{2} & 8 & 91.9525 & 91.9525 \\
\hline & 7.2 & 91.8044 & 91.8078 \\
\hline & 6.4 & 92.2407 & 92.2407 \\
\hline & 5.6 & 92.5206 & 92.5206 \\
\hline & 4.8 & 92.8081 & 92.8081 \\
\hline & 4.2 & 92.5115 & 92.5118 \\
\hline \multirow{6}{*}{3} & 8 & 91.9861 & 91.9861 \\
\hline & 7 & 92.1882 & 92.1882 \\
\hline & 6 & 92.4055 & 92.4055 \\
\hline & 5 & 92.7594 & 92.7593 \\
\hline & 4 & 92.6883 & 92.6883 \\
\hline & 3 & 92.3523 & 92.3523 \\
\hline
\end{tabular}
damping as shown in Table 4.

TABLE 3

THE CUMULATIVE MASS PARTICIPATION FACTOR FOR THE FIRST

\begin{tabular}{|c|c|c|c|c|c|c|c|}
\hline Cluster & $\begin{array}{l}\text { Aspect } \\
\text { ratio }\end{array}$ & $\begin{array}{c}f_{1} \\
\text { (Hertz) }\end{array}$ & $\begin{array}{c}f_{13} \\
\text { (Hertz) }\end{array}$ & $\xi_{1}$ & $\xi_{13}$ & $\alpha$ & $\beta$ \\
\hline \multirow{6}{*}{1} & 6.0 & 0.152898 & 2.005533 & 1.39 & 3.58 & 0.0216 & 0.00546 \\
\hline & 5.4 & 0.165590 & 2.008229 & 1.46 & 3.57 & 0.0244 & 0.005505 \\
\hline & 4.8 & 0.181620 & 2.02333 & 1.55 & 3.59 & 0.0282 & 0.005473 \\
\hline & 4.2 & 0.202281 & 2.043768 & 1.68 & 3.67 & 0.0338 & 0.005511 \\
\hline & 3.6 & 0.229522 & 2.075374 & 1.86 & 3.8 & 0.0419 & 0.005476 \\
\hline & 3.0 & 0.30016 & 2.117161 & 2.1 & 4.02 & 0.054 & 0.00573 \\
\hline \multirow{6}{*}{2} & 8.0 & 0.116711 & 1.712913 & 1.27 & 3.53 & 0.0152 & 0.006429 \\
\hline & 7.2 & 0.129968 & 1.719728 & 1.3 & 3.37 & 0.0172 & 0.006091 \\
\hline & 6.4 & 0.142109 & 1.74877 & 1.35 & 3.33 & 0.0194 & 0.005901 \\
\hline & 5.6 & 0.158877 & 1.812241 & 1.43 & 3.36 & 0.0228 & 0.005725 \\
\hline & 4.8 & 0.17734 & 1.837507 & 1.55 & 3.44 & 0.0274 & 0.005754 \\
\hline & 4.0 & 0.214289 & 1.965475 & 1.73 & 3.57 & 0.0365 & 0.00542 \\
\hline \multirow{6}{*}{3} & 8.0 & 0.116249 & 1.446684 & 1.27 & 3.16 & 0.0149 & 0.006778 \\
\hline & 7.0 & 0.132188 & 1.527470 & 1.31 & 3.11 & 0.0174 & 0.006292 \\
\hline & 6.0 & 0.147507 & 1.536984 & 1.39 & 3.09 & 0.0205 & 0.00618 \\
\hline & 5.0 & 0.170101 & 1.638429 & 1.52 & 3.23 & 0.0256 & 0.006034 \\
\hline & 4.0 & 0.198747 & 1.690392 & 1.73 & 3.42 & 0.0336 & 0.006142 \\
\hline & 3.0 & 0.259629 & 1.870904 & 2.1 & 3.79 & 0.0524 & 0.006064 \\
\hline
\end{tabular}

TABLE 4

DAMPING PARAMETERS FOR ALL MODELS.

\section{ANALYSIS OF RESUlts}

For comparison between the original (three dimensional) and reduced model, four methods are used in the analysis as:

1-Modal (free vibration)

2-Equivalent lateral force (ELF)

3-Dynamic response spectrum (RSP)

4-Linear time history (LTH)

The heights of the analyzed buildings are ranged from 120.0 $\mathrm{m}$ to $320.0 \mathrm{~m}$ with inclinations of diagrid ranged between $60.94^{\circ}$ and $71.56^{\circ}$.

The results showed that,

- With reference to Table 5:

For the first method (modal analysis),

A good agreement is noticed between the original and reduced models for the first mode period of vibration. The error ranges between $2.36 \%$ and $-14.02 \%$ for all buildings.

- With references to Fig. 15 and Table 6:

For the second method (equivalent lateral force),

The top displacement error between the original and reduced models ranges from $5.59 \%$ to $-2.08 \%$ with building heights of $120.0 \mathrm{~m}$ to $240.0 \mathrm{~m}$ in case of half reduction. For quarter reduction, it ranges from $3.64 \%$ to $-7.39 \%$. For comparison between two models the results showed that the base shear error ranges from $-0.15 \%$ to $-0.32 \%$ (half reduction) and $-1.12 \%$ to $-1.33 \%$ (quarter reduction).

The top displacement error between the original and reduced models ranges from $5.15 \%$ to $-3.63 \%$ with building height of $160.0 \mathrm{~m}$ to $320.0 \mathrm{~m}$ in case of half reduction. For quarter reduction, it ranges from $9.7 \%$ to $-1.79 \%$. For comparison between two models the results showed that the base shear error ranges from $-0.29 \%$ to $-0.34 \%$ (half reduction) and $-1.29 \%$ to $-1.36 \%$ (quarter reduction).

The top displacement error between the original and reduced models ranges from $3.17 \%$ to $19.02 \%$ with building height of $120.0 \mathrm{~m}$ to $320.0 \mathrm{~m}$ in case of fifth reduction. For comparison between two models the results showed that the base shear error ranges from $-0.15 \%$ to $-0.32 \%$ in case of fifth reduction. 
The equivalent lateral force is a simple method to perform the seismic analysis but, it neglects the contributions of the higher modes.

- With references to Fig. 16 and Table 7:

For the third method (dynamic response spectrum),

The top displacement error between the original and reduced models ranges from $1.42 \%$ to $-0.6 \%$ with building height of $120.0 \mathrm{~m}$ to $240.0 \mathrm{~m}$ in case of half reduction. For quarter reduction, it ranges from $4.02 \%$ to $-2.63 \%$. For comparison between the original and reduced models the results showed that the base shear error ranges from $1.95 \%$ to $-12.01 \%$ (half reduction) and $7.77 \%$ to $-7.95 \%$ (quarter reduction).

The top displacement error between the original and reduced models ranges from $0.61 \%$ to $-1.85 \%$ with building height of $160.0 \mathrm{~m}$ to $320.0 \mathrm{~m}$ in case of half reduction. For quarter reduction, it ranges from $2 \%$ and $-3.76 \%$. For comparison between the original and reduced models the results showed that the base shear error ranges from $-0.12 \%$ to $3.96 \%$ (half reduction) and $0.9 \%$ to $3.39 \%$ (quarter reduction).

The top displacement error between the original and reduced models ranges from $0.42 \%$ to $-5.31 \%$ with building height of $160.0 \mathrm{~m}$ to $320.0 \mathrm{~m}$ in case of half reduction. For quarter reduction, it ranges from $4.28 \%$ to $-14.98 \%$. For comparison between two models the results showed that the base shear error ranges from $4.28 \%$ to $-14.98 \%$ (half reduction) and $12.23 \%$ to $-22.75 \%$ (quarter reduction).

The top displacement error between the original and reduced models ranges from $14.95 \%$ to $-15.96 \%$ with building height of $120.0 \mathrm{~m}$ to $320.0 \mathrm{~m}$ in case of fifth reduction. For comparison between two models the results showed that: the
The top displacement error at between the original and reduced models ranges from $3.11 \%$ to $-9.13 \%$ with building height of $120.0 \mathrm{~m}$ to $320.0 \mathrm{~m}$ in case of fifth reduction. For comparison between two models the results showed that the base shear error ranges from $5.26 \%$ to $17.07 \%$ in case of fifth reduction. The response spectrum is a good seismic approach to predict the maximum responses in the linear zone. It includes the contributions of the higher modes for the maximum response.

- With references to Figs. 17 to 19 and Table 8:

For the fourth method (linear time history),

The top displacement error between the original and reduced models ranges from $7.39 \%$ to $-9.23 \%$ with building height of $120.0 \mathrm{~m}$ to $240.0 \mathrm{~m}$ in case of half reduction. For quarter reduction, it ranges from $5.65 \%$ to $-16.2 \%$. For comparison between two models the results showed that the base shear error ranges from $16.02 \%$ to $-10.09 \%$ (half reduction) and $16.57 \%$ to $-14.11 \%$ (quarter reduction).

base shear error ranges from $25 \%$ to $16.89 \%$ in case of fifth reduction.

The linear time history could predict the behavior of the buildings along the time.

The obtained results can give an overview for the behavior of diagrid buildings with less effort in modeling and analysis rather than the $3 \mathrm{D}$ complex detailed modeling. The reduced model can give an approximation on the modes of vibration, the lateral deformations and initial checks on the selected cross sections based on initial internal force and the overall flexibility of the model.

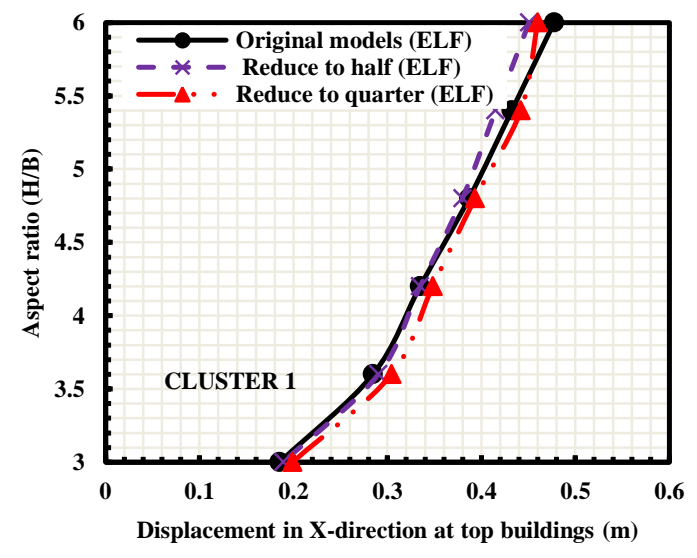

(a) Lateral displacement at top buildings

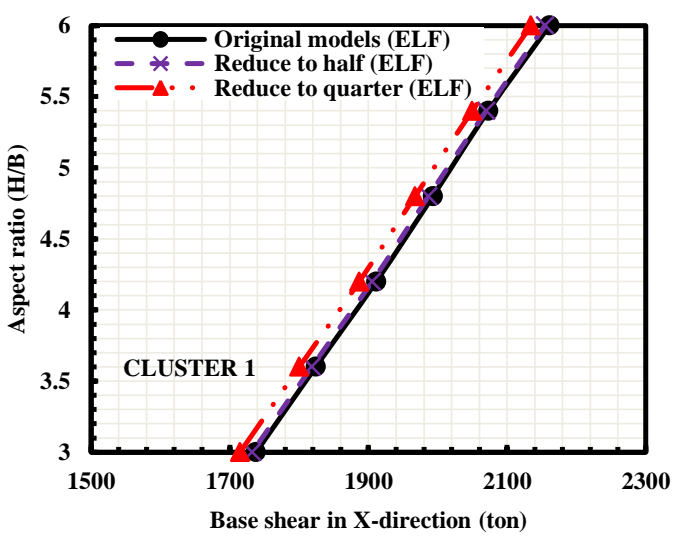

(b) Lateral base shear

Fig. 15. Cluster 1: top displacement and base shear (ELF) 


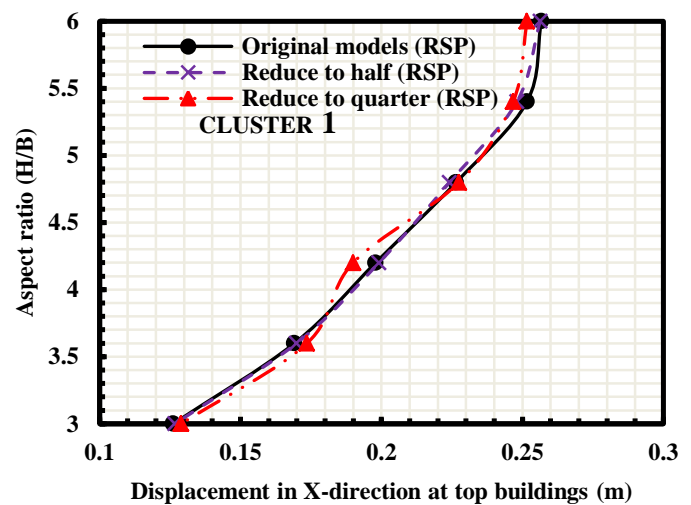

(a) Lateral displacement at top buildings

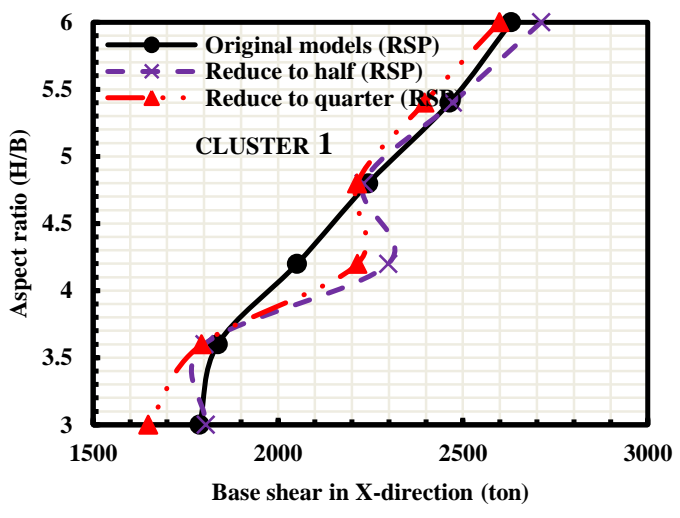

(b) Lateral base shear

Fig. 16. Cluster 1: top displacement and base shear (RSP)
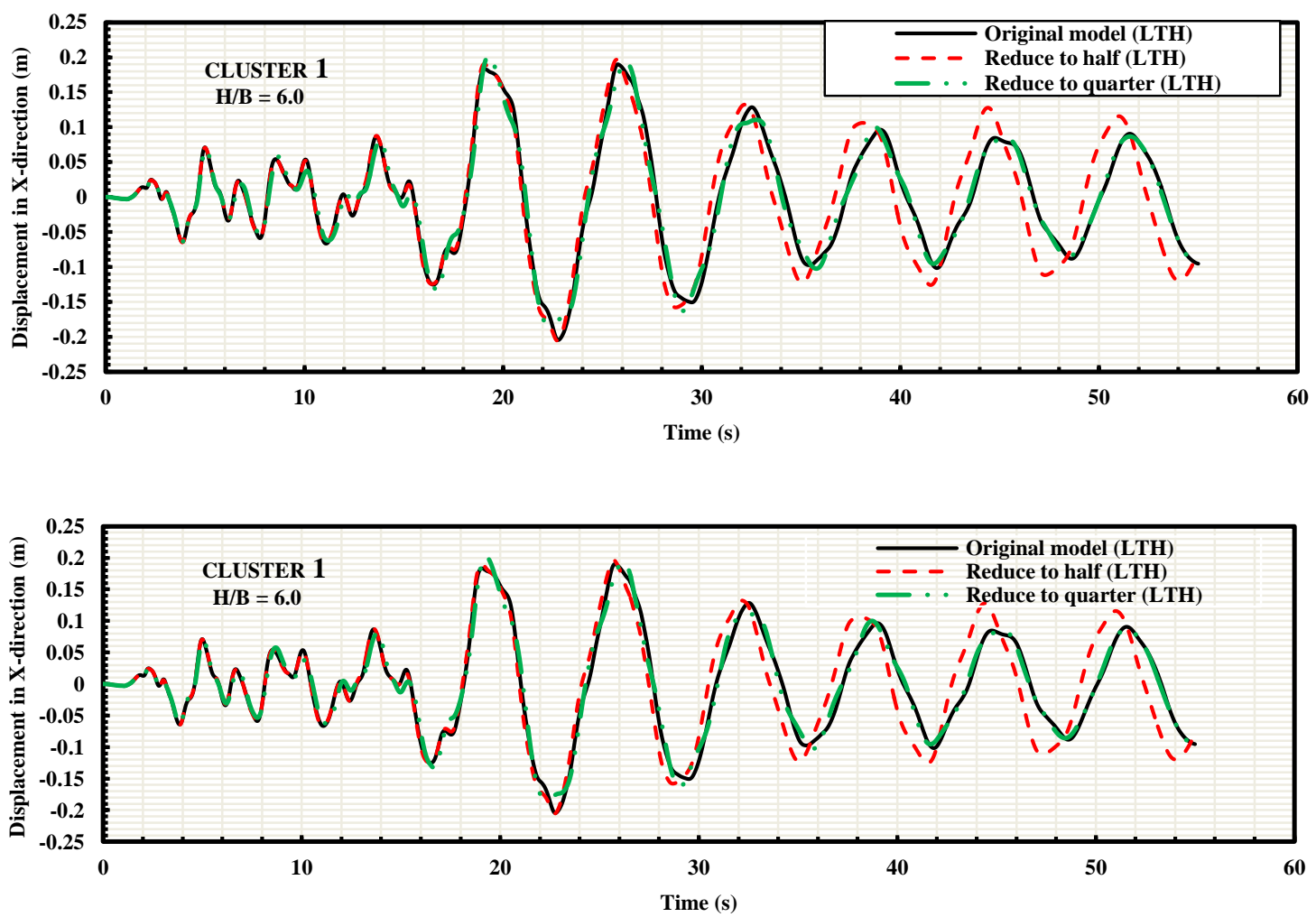

(a) Lateral displacement history at top building

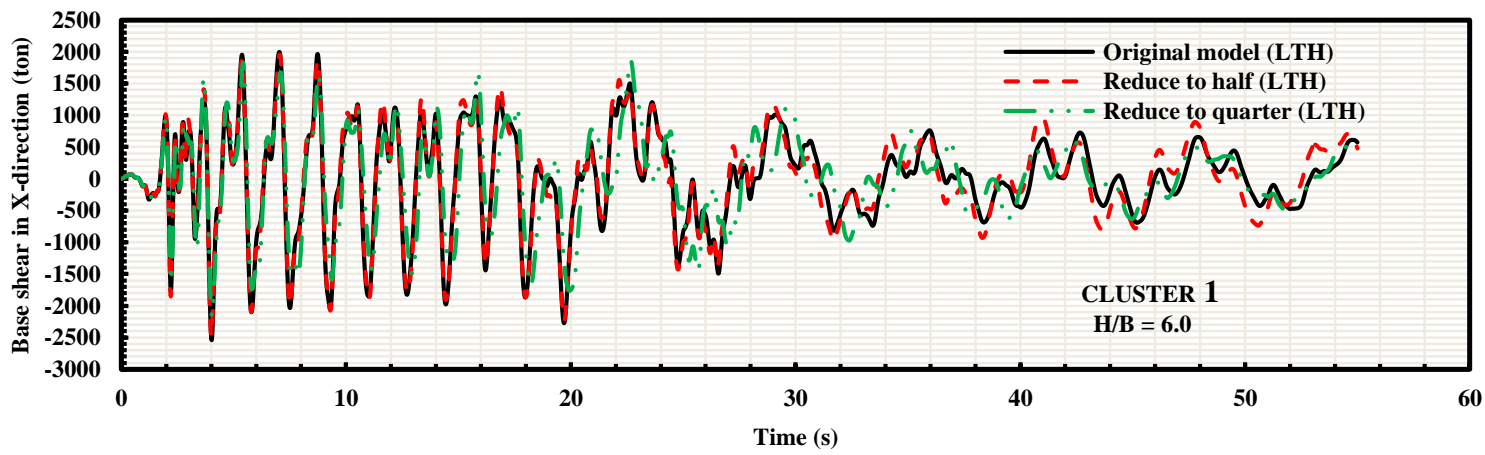

(b) Lateral base shear history

Fig. 17. Cluster 1: Building with height of $240 \mathrm{~m}(\mathrm{LTH})$ 


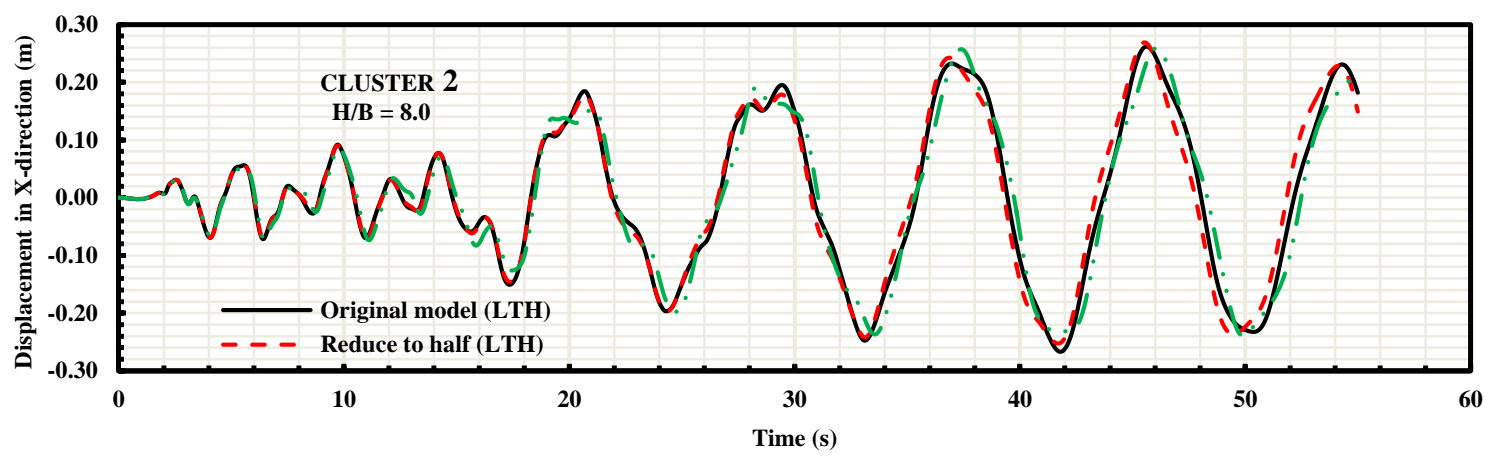

(a) Lateral displacement history at top building

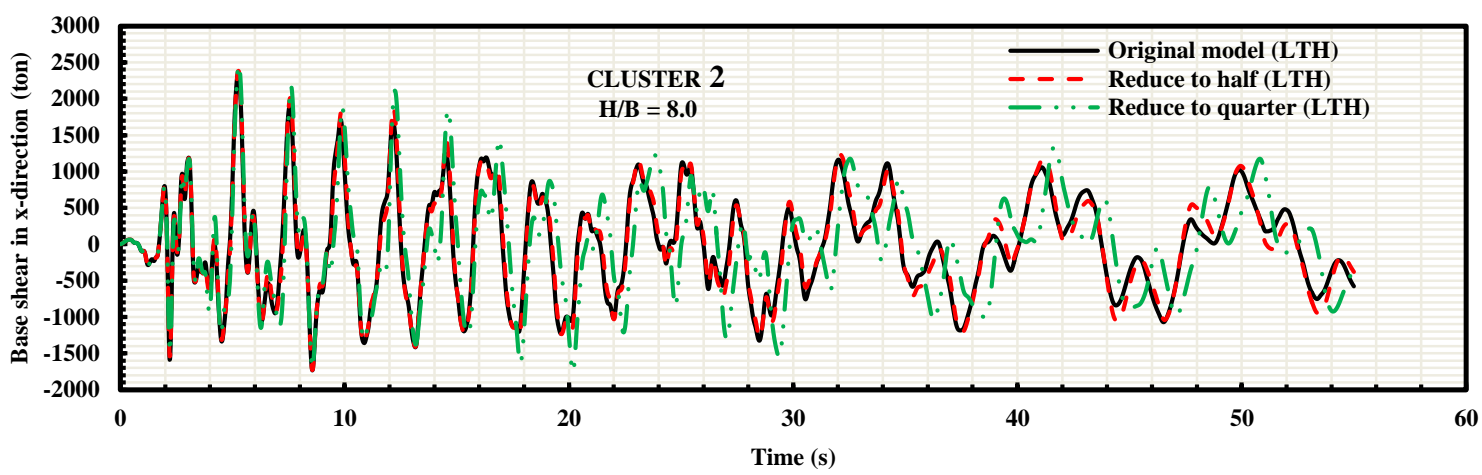

(b) Lateral base shear history

Fig. 18. Cluster 2: Building with height of 320m (LTH)

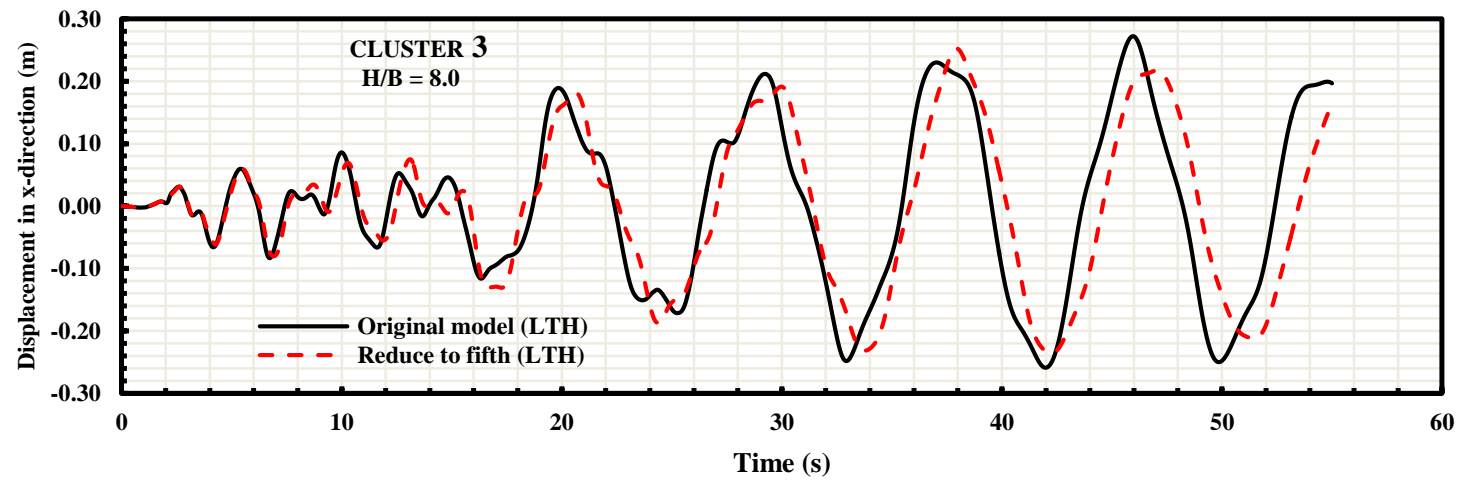

(a) Lateral displacement history at top building

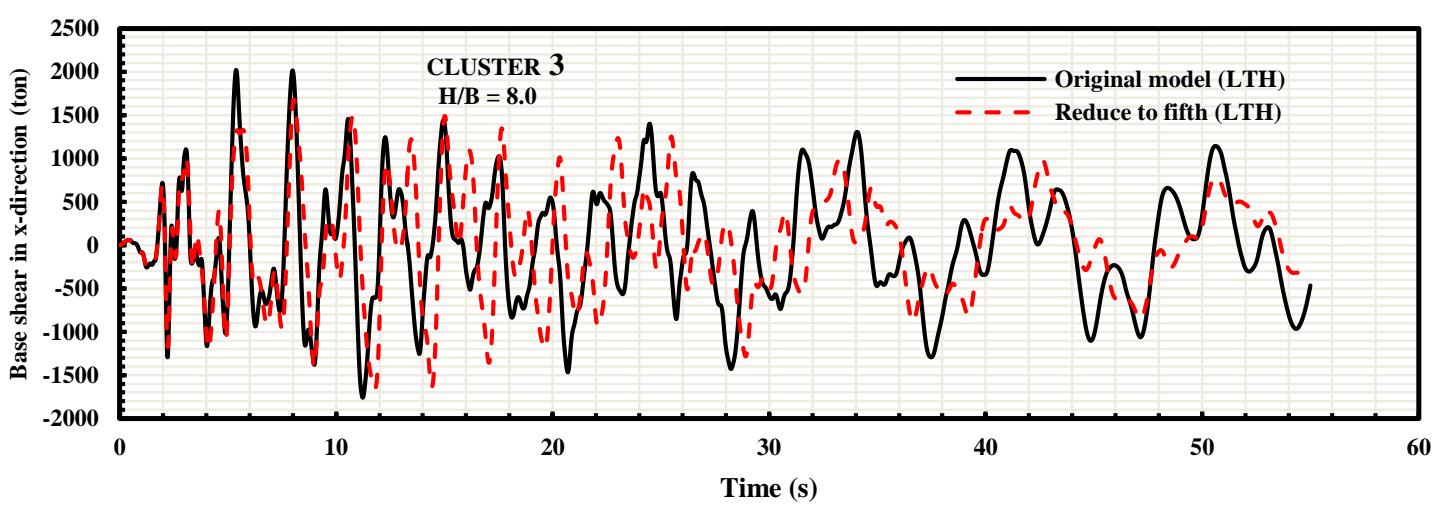

(b) Lateral base shear history

Fig. 19. Cluster 3: Building with height of $320 \mathrm{~m}$ (LTH) 
TABLE 5

First Mode Period of Vibration for All Buildings

\begin{tabular}{|c|c|c|c|c|c|c|c|c|c|c|}
\hline \multicolumn{4}{|c|}{ Cluster 1} & \multicolumn{4}{|c|}{ Cluster 2} & \multicolumn{3}{|c|}{ Cluster 3} \\
\hline $\mathrm{H} / \mathrm{B}$ & $\begin{array}{l}\text { Original } \\
\text { (s) }\end{array}$ & $\begin{array}{c}\text { Reduce to half } \\
\text { (s) }\end{array}$ & $\begin{array}{l}\text { Reduce to } \\
\text { quarter (s) }\end{array}$ & $\mathrm{H} / \mathrm{B}$ & $\begin{array}{l}\text { Original } \\
\text { (s) }\end{array}$ & $\begin{array}{c}\text { Reduce to } \\
\text { half(s) }\end{array}$ & $\begin{array}{l}\text { Reduce to } \\
\text { quarter (s) }\end{array}$ & $\mathrm{H} / \mathrm{B}$ & $\begin{array}{l}\text { Original } \\
(\mathrm{s})\end{array}$ & $\begin{array}{l}\text { Reduce to } \\
\text { Fifth (s) }\end{array}$ \\
\hline 6 & 6.54 & 6.39 & 6.53 & 8 & 8.57 & 8.46 & 8.64 & 8 & 8.60 & 8.94 \\
\hline 5.4 & 6.04 & 5.95 & 6.22 & 7.2 & 7.69 & 7.63 & 7.84 & 7 & 7.56 & 7.95 \\
\hline 4.8 & 5.51 & 5.49 & 5.66 & 6.4 & 7.04 & 7.04 & 7.25 & 6 & 6.78 & 7.24 \\
\hline 4.2 & 4.94 & 4.98 & 5.15 & 5.6 & 6.29 & 6.35 & 6.61 & 5 & 5.88 & 6.38 \\
\hline 3.6 & 4.36 & 4.44 & 4.62 & 4.8 & 5.64 & 5.75 & 5.98 & 4 & 5.03 & 5.58 \\
\hline 3 & 3.33 & 3.40 & 3.55 & 4 & 4.67 & 4.83 & 5.02 & 3 & 3.85 & 4.39 \\
\hline
\end{tabular}

TABLE 6

DIVERGENCE BETWEEN THE ORIGINAL AND REDUCED MODELS FOR (ELF)

\begin{tabular}{|c|c|c|c|c|c|c|c|c|c|c|c|c|}
\hline & \multicolumn{4}{|c|}{ Cluster 1 (Error\%) } & \multicolumn{5}{|c|}{ Cluster 2 (Error\%) } & \multicolumn{3}{|c|}{ Cluster 3 (Error\%) } \\
\hline \multirow{2}{*}{$\begin{array}{c}\text { Aspect } \\
\text { ratio } \\
\text { (H/B) }\end{array}$} & \multicolumn{2}{|c|}{ Reduce to half } & \multicolumn{2}{|c|}{$\begin{array}{l}\text { Reduce to } \\
\text { quarter }\end{array}$} & \multirow{2}{*}{$\begin{array}{c}\text { Aspect } \\
\text { ratio } \\
(\mathbf{H} / \mathbf{B})\end{array}$} & \multicolumn{2}{|c|}{$\begin{array}{l}\text { Reduce to } \\
\text { half }\end{array}$} & \multicolumn{2}{|c|}{$\begin{array}{l}\text { Reduce to } \\
\text { quarter }\end{array}$} & \multirow{2}{*}{$\begin{array}{c}\text { Aspect } \\
\text { ratio } \\
\text { (H/B) }\end{array}$} & \multicolumn{2}{|c|}{$\begin{array}{l}\text { Reduce to } \\
\text { fifth }\end{array}$} \\
\hline & $\begin{array}{l}\text { Disp. } \\
\text { at top }\end{array}$ & $\begin{array}{l}\text { Base } \\
\text { shear }\end{array}$ & $\begin{array}{l}\text { Disp. } \\
\text { at top }\end{array}$ & Base shear & & $\begin{array}{l}\text { Disp. } \\
\text { at top }\end{array}$ & base shear & $\begin{array}{l}\text { Disp. } \\
\text { at top }\end{array}$ & base shear & & $\begin{array}{l}\text { Disp. } \\
\text { at top }\end{array}$ & base shear \\
\hline 6 & 5.59 & -0.30 & 3.64 & -1.24 & 8 & -3.63 & -0.33 & -1.79 & -1.29 & 8 & 3.17 & -1.52 \\
\hline 5.4 & 3.99 & -0.15 & -2.21 & -1.12 & 7.2 & -2.75 & -0.29 & -0.05 & -1.32 & 7 & 5.10 & -1.63 \\
\hline 4.8 & 1.83 & -0.31 & -1.64 & -1.29 & 6.4 & -1.21 & -0.34 & 1.98 & -1.36 & 6 & 8.12 & -1.53 \\
\hline 4.2 & -0.01 & -0.31 & -4.02 & -1.28 & 5.6 & 0.26 & -0.34 & 5.45 & -1.35 & 5 & 10.66 & -1.52 \\
\hline 3.6 & -2.02 & -0.32 & -6.93 & -1.30 & 4.8 & 2.23 & -0.33 & 6.98 & -1.34 & 4 & 14.47 & -1.50 \\
\hline 3 & -2.08 & $\begin{array}{c}-0.32 \\
\end{array}$ & $\begin{array}{l}-7.39 \\
\end{array}$ & $\begin{array}{l}-1.33 \\
\end{array}$ & 4 & 5.15 & $\begin{array}{c}-0.33 \\
\end{array}$ & 9.70 & -1.36 & 3 & 19.02 & -1.52 \\
\hline
\end{tabular}

TABLE 7

DIVERGENCE BETWEEN ORIGINAL MODELS AND SIMPLE MODELS FOR (RSP)

\begin{tabular}{|c|c|c|c|c|c|c|c|c|c|c|c|c|}
\hline \multicolumn{5}{|c|}{ Cluster 1 (Error \%) } & \multicolumn{5}{|c|}{ Cluster 2 (Error \%) } & \multicolumn{3}{|c|}{ Cluster 3 (Error\%) } \\
\hline \multirow{2}{*}{$\begin{array}{c}\text { Aspect } \\
\text { ratio } \\
\text { (H/B) }\end{array}$} & \multicolumn{2}{|c|}{$\begin{array}{l}\text { Reduce to } \\
\text { half }\end{array}$} & \multicolumn{2}{|c|}{$\begin{array}{c}\text { Reduce to } \\
\text { quarter }\end{array}$} & \multirow{2}{*}{$\begin{array}{c}\text { Aspect } \\
\text { ratio } \\
\text { (H/B) }\end{array}$} & \multicolumn{2}{|c|}{$\begin{array}{c}\text { Reduce to } \\
\text { half }\end{array}$} & \multicolumn{2}{|c|}{$\begin{array}{l}\text { Reduce to } \\
\text { quarter }\end{array}$} & \multirow{2}{*}{$\begin{array}{c}\text { Aspect } \\
\text { ratio } \\
(\mathbf{H} / \mathbf{B})\end{array}$} & \multicolumn{2}{|c|}{ Reduce to fiftl } \\
\hline & $\begin{array}{c}\text { Disp. } \\
\text { at } \\
\text { top\% }\end{array}$ & $\begin{array}{c}\text { Base } \\
\text { shear\% }\end{array}$ & $\begin{array}{c}\text { Disp. } \\
\text { at } \\
\text { top\% }\end{array}$ & $\begin{array}{c}\text { Base } \\
\text { shear\% }\end{array}$ & & $\begin{array}{c}\text { Disp. } \\
\text { at } \\
\text { top\% }\end{array}$ & $\begin{array}{c}\text { base } \\
\text { shear\% }\end{array}$ & $\begin{array}{c}\text { Disp. } \\
\text { at } \\
\text { top\% }\end{array}$ & $\begin{array}{c}\text { base } \\
\text { shear\% }\end{array}$ & & $\begin{array}{c}\text { Disp. } \\
\text { at } \\
\text { top\% }\end{array}$ & $\begin{array}{c}\text { base } \\
\text { shear\% }\end{array}$ \\
\hline 6 & 0.16 & -3.08 & 1.97 & 1.21 & 8 & 0.61 & -0.12 & 2.00 & 0.90 & 8 & 2.62 & 2.39 \\
\hline 5.4 & 1.42 & -0.37 & 1.97 & 2.76 & 7.2 & 0.77 & 1.99 & 2.20 & 0.48 & 7 & 2.79 & 2.77 \\
\hline 4.8 & 1.04 & 0.56 & -0.46 & 1.34 & 6.4 & 0.83 & 2.59 & 2.13 & 1.53 & 6 & 3.11 & 3.01 \\
\hline 4.2 & -0.60 & -12.01 & 4.02 & -7.95 & 5.6 & 1.09 & 3.93 & 2.85 & 3.39 & 5 & 1.22 & 5.26 \\
\hline 3.6 & -0.44 & 1.95 & -2.63 & 2.37 & 4.8 & -0.71 & 2.94 & -2.67 & 2.87 & 4 & -6.66 & 4.26 \\
\hline 3 & -0.44 & -0.94 & -2.27 & 7.77 & 4 & -1.85 & 3.96 & -3.76 & 2.40 & 3 & -9.13 & 17.07 \\
\hline
\end{tabular}

TABLE 8

DIVERGENCE FOR THE MAXIMUM ABSOLUTE VALUES BETWEEN ORIGINAL MODELS AND SIMPLE MODELS FOR (SCALED EL CENTRO).

\begin{tabular}{|c|c|c|c|c|c|c|c|c|c|c|c|c|}
\hline \multicolumn{5}{|c|}{ Cluster 1 (Error\%) } & \multicolumn{5}{|c|}{ Cluster 2 (Error\%) } & \multicolumn{3}{|c|}{ Cluster 3 (Error\%) } \\
\hline \multirow{2}{*}{$\begin{array}{c}\text { Aspect } \\
\text { ratio } \\
\text { (H/B) }\end{array}$} & \multicolumn{2}{|c|}{ Reduce to half } & \multicolumn{2}{|c|}{$\begin{array}{l}\text { Reduce to } \\
\text { quarter }\end{array}$} & \multirow{2}{*}{$\begin{array}{c}\text { Aspect } \\
\text { ratio } \\
(\mathbf{H} / \mathbf{B})\end{array}$} & \multicolumn{2}{|c|}{$\begin{array}{c}\text { Reduce to } \\
\text { half }\end{array}$} & \multicolumn{2}{|c|}{$\begin{array}{l}\text { Reduce to } \\
\text { quarter }\end{array}$} & \multirow{2}{*}{$\begin{array}{l}\text { Aspect } \\
\text { ratio } \\
(\mathbf{H} / \mathbf{B})\end{array}$} & \multicolumn{2}{|c|}{ Reduce to fifth } \\
\hline & $\begin{array}{l}\text { Disp. } \\
\text { at } \\
\text { top\% }\end{array}$ & $\begin{array}{c}\text { Base } \\
\text { shear\% }\end{array}$ & $\begin{array}{c}\text { Disp. } \\
\text { At } \\
\text { top\% }\end{array}$ & $\begin{array}{c}\text { Base } \\
\text { shear\% }\end{array}$ & & $\begin{array}{l}\text { Disp. } \\
\text { at } \\
\text { top\% }\end{array}$ & $\begin{array}{c}\text { base } \\
\text { shear\% }\end{array}$ & $\begin{array}{l}\text { Disp. } \\
\text { at } \\
\text { top\% }\end{array}$ & $\begin{array}{c}\text { base } \\
\text { shear\% }\end{array}$ & & $\begin{array}{l}\text { Disp. } \\
\text { at top\% }\end{array}$ & $\begin{array}{c}\text { base } \\
\text { shear\% }\end{array}$ \\
\hline 6 & -0.48 & 2.20 & 1.32 & 14.95 & 8 & -0.77 & -1.38 & 3.06 & -4.91 & 8 & 7.25 & 16.89 \\
\hline 5.4 & -1.58 & -0.34 & 1.69 & 16.54 & 7.2 & -0.98 & -12.02 & -9.02 & -17.20 & 7 & -15.96 & 9.77 \\
\hline 4.8 & -4.84 & -9.36 & -6.24 & -14.11 & 6.4 & 0.42 & -14.98 & -5.35 & -22.75 & 6 & 7.18 & 8.52 \\
\hline 4.2 & 7.39 & 16.02 & 5.65 & 16.57 & 5.6 & -0.20 & 4.28 & 7.38 & 5.33 & 5 & 14.32 & 9.65 \\
\hline 3.6 & -9.23 & -8.74 & -16.20 & -7.06 & 4.8 & $\begin{array}{l}-3.78 \\
\end{array}$ & 1.86 & -7.75 & $\begin{array}{l}-0.81 \\
\end{array}$ & 4 & -9.53 & 25.00 \\
\hline 3 & -6.04 & -10.09 & -2.70 & 1.59 & 4 & -5.31 & 0.28 & -2.80 & 12.23 & 3 & 14.95 & 5.45 \\
\hline
\end{tabular}

\section{CONCLUSION}

The results showed that,

- $\quad$ The using of reduced model instead the three dimensional model had a significant effect in all obtained results saving in the degrees of freedom and time executed.
- The equivalent lateral force is the best methods in comparison with other mentioned method in this paper because is independent on the natural frequencies for higher modes.

- The amount of reduction percentage may affect the results. 
- A good agreement is noticed in case of reduction to $50 \%$.

- All obtained results are used as a guide for preliminary analysis to reach the best representative for real structure. Then, the exact three dimensions for structures must take into consideration to make the best analysis.

\section{Nomenclature}

Aspect ratio
$\mathrm{K}_{\mathrm{eq}}$
$\mathrm{m}_{\mathrm{eq}}$
$\mathrm{m}_{\mathrm{s}+\mathrm{b}}$
$\mathrm{m}_{\mathrm{d}}$
$\mathrm{K}_{\mathrm{d}}$
$\mathrm{M}$
$\mathrm{L}_{\mathrm{d}}$
$\mathrm{S}$

$\alpha_{h}$

$\mathrm{H}$

$\mathrm{N}_{\mathrm{F}}$

$\delta$

$\mathrm{E}$

B

h

$\theta$

$\mathrm{V}$

$\mathrm{N}_{\mathrm{W}}$

$\mathrm{N}_{\mathrm{f}}$

$\mathrm{S}_{\mathrm{DS}}$

$\mathrm{S}_{\mathrm{D} 1}$

G

$\mathrm{C}_{\mathrm{t}}$

$\mathrm{x}$

$\mathrm{R}$

$\mathrm{I}_{\mathrm{e}}$

$\mathrm{T}_{\mathrm{L}}$

[C]

[M]

[K]

$\alpha_{m}$

$\beta_{k}$

$\xi_{1}$

$\xi_{m}$

$\xi(f)$

$\gamma_{m}$

$f_{n}$

$f_{1}$

ELF

RSP

LTH

The ratio between building height and width

Equivalent stiffness for the reduced model

Equivalent mass for the reduced model

Total mass of slab and beams for considered story

Mass of diagrid element

Stiffness for diagrid element

The moment at level of consideration

The diagrid member length

The ratio between bending and shear deformations at top of the building

A factor used for the allowable lateral

displacement at top constrained to 500

The Building height

The number of diagonals on flange side

An estimate of the contribution of the diagonals on each web to the bending rigidity is made by adding one extra diagonal on each flange;

The modulus of elasticity

The plan dimension of the building parallel to the considered lateral load direction

The module height

The angle of diagrid elements

The shear force at level of consideration

The number of diagonals on web side

The number of diagonals on flange side

Design earthquake spectral response acceleration parameter at short period.

Design earthquake spectral response acceleration

parameter at 1 second.

Gravity acceleration.

Building period coefficient.

Constant depends on structure type.

Response modification factor.

Importance factor.

Long period transition.

Damping matrix of the structure.

Mass matrix of the structure.

Stiffness matrix of the structure.

Mass constant for Rayleigh damping.

Stiffness constant for Rayleigh damping.

Damping ratio for the first mode.

Damping ratio for the $\mathrm{m}^{\text {th }}$ significant higher

mode considered for the analysis.

Damping ratio used for the higher modes.

Constant depends on structural system.

Natural frequency for the nth significant mode.

Natural frequency for the first mode.

Equivalent lateral force.

Dynamic response spectrum.

Linear time history.

\section{AUTHORS CONTRIBUTION}

Mohamed Naguib Abou El-Saad, Ahmed Amin Ghaleb and Ahmed Mahmoud Yousef conceived of the presented idea. Sameh Lotfy Mahmoud developed the theory and performed the computations and analyses. Mohamed Naguib Abou El-Saad, Ahmed Amin Ghaleb verified the methods of analysis. Ahmed Amin Ghaleb and Mohamed Naguib Abou El-Saad have supervised the findings of this work. All authors discussed the results and contributed to the final manuscript. Sameh Lotfy Mahmoud wrote the manuscript with support from Mohamed Naguib Abou El-Saad

\section{REFERENCES}

[1] K. S. Moon, J. J. Connor, and J. E. Fernandez, "Diagrid structural systems for tall buildings: Characteristics and methodology for preliminary design," Struct. Des. Tall Spec. Build., 2007.

[2] C. Zhang, F. Zhao, and Y. Liu, "Diagrid tube structures composed of straight diagonals with gradually varying angles," Struct. Des. Tall Spec. Build., 2012.

[3] J. Kim and Y. H. Lee, "Seismic performance evaluation of diagrid system buildings," Struct. Des. Tall Spec. Build., 2012.

[4] G. M. Montuori, E. Mele, G. Brandonisio, and A. De Luca, "Design criteria for diagrid tall buildings: Stiffness versus strength," Struct. Des. Tall Spec. Build., 2014.

[5] S. L. Mahmoud, M. N. Abo-El Saad, A. A. Ghaleb, and A. M. Yousef, "Reliable Drift of Diagrid Tall Buildings due to Seismic Load," Appl. Model. Simul., vol. 4, pp. 110-124, 2020.

[6] S. Gerasimidis, P. Pantidis, B. Knickle, and K. S. Moon, "Diagrid Structural System for High-Rise Buildings: Applications of a Simple Stiffness-based Optimized Design,” Int. J. High-Rise Build., 2016.

[7] K. Moon, "Design and Construction of Steel Diagrid Structures," in NSCC2009, 2009.

[8] D. Lee and S. Shin, "Advanced high strength steel tube diagrid using TRIZ and nonlinear pushover analysis," J. Constr. Steel Res., 2014.

[9] Y. J. Lee, J. Oh, H. H. Abdu, and Y. K. Ju, "Finite element analysis of optimized brace angle for the diagrid structural system," Int. J. Steel Struct., 2016.

[10] T. M. Boake, "The Emergence of the Diagrid - It's All About the Node," Int. J. High-Rise Build., 2016.

[11] W. Baker, C. Besjak, M. Sarkisian, P. Lee, and C.-S. Doo, "Proposed Methodology To Determine Seismic Performance Factors For Steel Diagrid Framed Systems," Counc. Tall Build. Urban Habitat, 2010.

[12] S. Sadeghi and F. R. Rofooei, "Quantification of the seismic performance factors for steel diagrid structures," J. Constr. Steel Res., 2018.

[13] E. Asadi and H. Adeli, "Seismic performance factors for low- to midrise steel diagrid structural systems," Struct. Des. Tall Spec. Build., 2018.

[14] M. Sohrabi-Haghighat and P. Ashtari, "Evaluation of Seismic Performance Factors for High-rise Steel Structures with Diagrid System," KSCE J. Civ. Eng., vol. 23, no. 11, pp. 4718-4726, 2019.

[15] K. S. Moon, "Material-saving design strategies for tall building structures," in CTBUH 2008, 8th World Congress - Tall and Green: Typology for a Sustainable Urban Future, Congress Proceedings, 2008.

[16] K. Jani and P. V. Patel, "Analysis and design of diagrid structural system for high rise steel buildings," in Procedia Engineering, 2013, vol. 51, pp. 92-100.

[17] G. Milana, P. Olmati, K. Gkoumas, and F. Bontempi, "Ultimate capacity of diagrid systems for tall buildings in nominal configuration and damaged state," Period. Polytech. Civ. Eng., 2015.

[18] IS:800-2007, General Construction in Steel - Code of Practice. New Delhi: Bureau of Indian Standard, 2007.

[19] M. Hosseini and A. A. Larki, "Physically simplified model of multistory buildings for their quick dynamic analysis," in ECCOMAS Thematic Conference - COMPDYN 2011: 3rd International Conference on Computational Methods in Structural Dynamics and Earthquake Engineering: An IACM Special Interest Conference, Programme, 2011, no. May, pp. 26-28.

[20] CSI, "SAP2000. Analysis Reference Manual," CSI: Berkeley (CA, USA): Computers and Structures INC. 2019.

[21] American Society for Testing and Materials, "ASTM A500-93, Standard Specification for cold-formed welded and seamless carbon steel structural tubing in rounds, square and rectangular shapes",ASTM . West Conshohocken, Pennsylvania, 2003. 
[22] American Society of Civil Engineers, ASCE 7-10. 2013.

[23] Center for Engineering Strong Motion Data, "Strongmotioncenter.org," 2019. [Online]. Available: https://strongmotioncenter.org/cgibin/CESMD/download_zip.pl?ElCentro_18May1940\%2FC_117r.zip=o n\&\&15158. [Accessed: 10-Oct-2019].

[24] Seismosignal, "Seismosoft.com," 2016. [Online]. Available: https://seismosoft.com/products/. [Accessed: 10-Oct-2019].

[25] ETABS2016, "Static and Dynamic Finite Element Analysis of Structures, Computers and Structures, Inc.” Berkeley, California, 2016.

[26] J. W. Strutt and R. Baron, The Theory of Sound, 1954th ed. New York: Dover publications, 1877.

[27] D. Bernal, M. Döhler, S. M. Kojidi, K. Kwan, and Y. Liu, "First mode damping ratios for buildings," Earthq. Spectra, 2015.

[28] C. Cruz and E. Miranda, "Evaluation of the Rayleigh damping model for buildings," Eng. Struct., 2017.

\section{Title Arabic:}

(نموذج مبئي مختزل ثلاثى الأبعاد لمبانى الشبكات المائلة العالية للتحليل

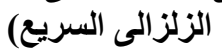

Arabic Abstract:

يقدم هذا البحث نموذج مختزل ثُلاثى الأبعاد للشبكات المائلة لتوفير الوقت وذاكرة

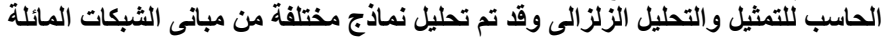

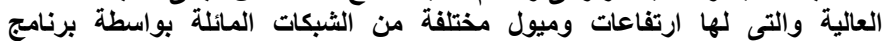
SAP2000

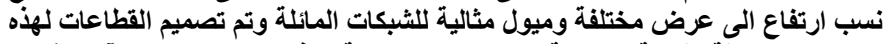

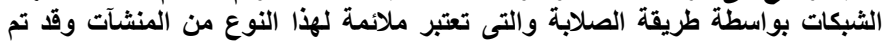

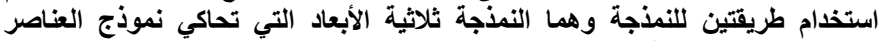

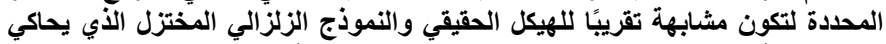

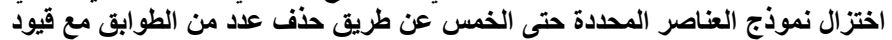

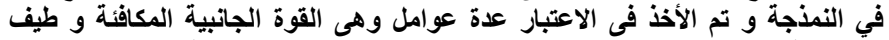

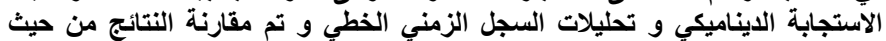

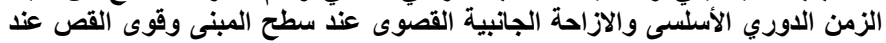

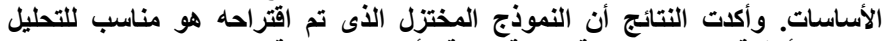

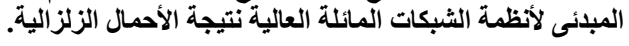

